Review

\title{
HUMAN DIROFILARIASIS: CURRENT SITUATION AND POSSIBILITIES FOR DIAGNOSIS
}

\author{
B. Chakarova ${ }^{1}$, M. Mitev ${ }^{2 *}$ \\ ${ }^{1}$ Department of Hygiene, Epidemiology, Microbiology, Parasitology and Infectious Diseases, \\ Faculty of Medicine, Trakia University, Stara Zagora, Bulgaria \\ ${ }^{2}$ Department of Medical Physics, Biophysics, Roentgenology and Radiology, Faculty of Medicine, \\ Department of Diagnostic Imaging, University Hospital 'St. Kirkovich', Trakia University, \\ Stara Zagora, Bulgaria
}

\begin{abstract}
Dirofilariasis in humans is a rarely diagnosed vector-borne zoonotic helminthic invasion. It is caused from filarial nematodes genus Dirofilaria \& Railliet Henry, 1911 (Onchocercidae, Nematoda). Usually, the life cycle of the parasite takes place between mosquitoes (Culicidae) and carnivores. The human is an accidental host for the dirofilaria wherefore microfilariae in his blood circulation are almost always absent. The pathology of dirofilariasis results from the accidental localization of immature worms in the human body. Dirofilaria immitis caused heart and pulmonary dirofilariasis, but Dirofilaria repens, $D$. tenuis, and others can are found in different parts of the human body. The spread and Dirofilariainvasive rates are undergone significant modifications affected by global climate change. Surgical extraction of the parasite in humans usually has a therapeutic effect, after which an etiological diagnosis is possible.

The aim of the study is to review the current situation of human dirofilariasis in clinical and epidemiological aspects and possibilities for diagnosis.
\end{abstract}

Key words: human dirofilariasis, clinical and epidemiological aspects dirofilariasis, diagnostic methods

\section{INTRODUCTION}

Dirofilariasis in humans (heartworm disease in $\operatorname{dogs})$ is a rarely diagnosed vector-borne zoonotic helminthic invasion. It is caused from filarial nematodes genus Dirofilaria \& Railliet Henry, 1911 (Onchocercidae, Nematoda). The first observation of $D$. repens-invasion in humans was probably reported in 1566 by Amato Lusitano, a Portuguese physician. He describes a worm nestled in the inner corner of an eye in a 3-year-old girl (1). In 1626 Birago incorrectly described the larval forms of roundworm specimens as Dioctophyme renale. In 1856 the genus was renamed as Filaria by Leidy and in 1911 as Dirofilaria by Railliet\&Henry (2). In the scientific literature, about 27 species of the genus Dirofilaria have been reported. Only three species of them are

\footnotetext{
*Correspondence to: Mitko Mitev, Department of Diagnostic Imaging, University Hospital "St. Kirkovich", Trakia University - Stara Zagora, 6000 Mobile: +35988 770 6079, E-mail: mitev.mitko69@gmail.com
}

diagnosed as parasites in humans: D. Immitis (Leidy, 1856), D. repens (Railliet \& Henry 1911) and D. tenuis (Chandler, 1942). Autochthonous $D$. repens infections have been found in $\operatorname{dogs}$ in most European countries, from Portugal to Russia (1). The main reservoir for $D$. repens in many countries in the world such as the United States, Southern Europe, Australia and Japan is the dog. (3). The life cycle of the parasite takes place between mosquitoes, which are intermediate hosts, and domestic and wild carnivores (such as foxes, wolves, raccoons) acting as definitive hosts. Adult nematodes give birth to microfilariae, which are transmitted by bloodsucking through intermediate hosts - over 70 potential species of mosquitoes of the family Culicidae (2, 4-12). D. immitis caused heart and pulmonary dirofilariasis, but $D$. repens, $D$. tenuis, and others can are found in subcutaneous nodules, or freely migrating (L3) filaria in the subcojuctiva, in the large vessels of the mesentery, peritoneum, the spermatic 
cord in the lungs and liver $(13,14)$. In Bulgaria only Dirofilaria repens is now found in humans - the people are sporadically infected. The dirofilariasis are distributed mainly in regions with warm climates and nowadays, the infection raises public health concerns in a number of countries $(6,15)$. D. repensinvasion in humans is accidental and the diagnosis of the disease creates problems for public health in a number of countries $(6,15$, 16).

The pathology of dirofilariasis results from the accidental localization of immature worms in the human body (8). The worms do not reach adulthood in human wherefore microfilariae in his blood circulation are almost always absent, which makes the etiological diagnosis extremely difficult. The distribution and Dirofilaria-invasive rates are undergone significant modifications affected by global climate change. Preliminary clinical diagnoses of patients with dirofilariasis mostly vary and the final diagnosis is staged after the surgical removal of the granuloma or the adult filaria. In most cases, the definitive diagnosis is obtained after the worm removal. Surgical extraction of the parasite in humans usually has a therapeutic effect, after which an etiological diagnosis is possible.

The aim of the study is to review current situation of human dirofilariasis in clinical and epidemiological aspects and possibilities for diagnosis.

\section{Current trends in the epidemiological characteristics and clinical manifestations of dirofilariasis}

From the three species of Dirofilaria, found as parasites in humans, in Europe, D. immitis has been reported from Southern Europe; $D$. repens - mainly from the countries of Mediterranean region and Eastern Europe (among dogs in Italy - 66\%, France - 22\%, Greece - 8\%, Spain - 4\%, etc.), (17). Georgieva et al. (1992), Georgieva et al. (2001), Kirkova et al. (2011); Radev et al. (2016); Iliev et al. (2017) explore wild animals, stray dogs and cats, from some regions in Bulgaria and establish among them invasion with $D$. immitis and $D$. repens (1822). Where heartworm disease is widespread in dog populations, there is a high risk for human infection, which creates serious public health problems in countries with growing populations of stray dogs $(3,23)$. D. tenuis was reported for the first time as a parasite in humans by Pistey (4). Over 70 potential species of mosquitoes of the genera Anopheles, Aedes, Culex and Coquillettidia, are vectots for Dirofilaria $s p$. In Europe, the most powerful vector for the transmission of Dirofilaria sp. (according to the literature) is Culex pipiens. The spread and Dirofilaria-invasive rates are undergone significant modifications affected by global climate change. Dirofilariasis is prevalent mainly in areas with warm climates at an average daily temperature above $14.8^{\circ} \mathrm{C}$ (below it the development of Dirofilaria stops) for 30 days (life expectancy of the vector) and a time interval of 130 days with increasing day (24). In the second half of the last century, more than 800 cases have been described in about 30 countries, with the age of the patients varying from 4 months to 100 years. People of working age are most often affected - around 40 years of age $(3,6,16)$. In North and South America, Australia, and parts of Africa, Japan, and Oceania, only D. immitis is widespread among dogs. In Northern Europe, China, Saudi Arabia and South Africa - only the species $D$. repens, and in Southern and Central Europe, Russia and the former southern Soviet republics, as well as in India are found as $D$. immitis and D. repens. $(3,16,25)$.

Vutchev et al. (2003 2004); Daskalova et al. (2006); Harizanov et al. (2010, 2014); Chakarova et al. (2013, 2014); Neichev et al. (2014); Kaftandjiev et al. (2016); Velev et al. (2019-a,b,c) are reported D. repens-invasion with varying location in humans in Bulgaria (26-37). Harizanov et al. (2010), Harizanov et al. (2014) presented a retrospective analysis of the reported 47 cases of human dirofilariasis, for the period 1973 - 2011. In 78.47\% of cases, the subcutaneous invasion was observed, followed by subconjunctival $(21.27 \%)$ and genital (4.25\%) infection. The authors reported a dominance of the upper body localization $(80.85 \%)$ over the lower body $(19.14 \%)$. A feature of ophthalmic dirofilariasis, according to the analysis made, was the subconjunctival location of the parasite and that it was not covered by the host response. The authors also found and reported of cases of localization of the parasite in the vitreous, lens and ocular space, etc. $(29,30)$. For 10 years before 2003 , Vutchev et al. (2003), Vutchev et al. (2004) described 12 cases with subcutaneous localization of the parasite, and for 20 years 22 cases $(26,27)$. Daskalova et al. (2006) reported a patient with cutaneous left lower 
eyelid dirofilariasis (28). Chakarova et al. (2013), Chakarova et al. (2014) and Kaftandjiev et al. (2016) described a rare localization of human dirofilariasis - in the epididymis $(31,32,34)$. Velev et al. $\left(2019^{\mathrm{a}}\right)$ described epididymal dirofilariasis in a child as the first case report from Bulgaria (35). Harizanov et al. (2010) presented 9 cases of $D$. repens infection in only one year - 2009 in Bulgaria (29). Chakarova et al. (2013), Chakarova et al. (2014), and Neichev et al. (2014) described 3 cases with subcutaneous localization of the parasite: in the area of the right mammary gland, the eyelid of the right eye, in the right epididymis and two with subconjunctival localization, all cases were in patients from South-eastern Bulgaria (31, 32, 33). According to Chakarova et al. (2014) the average duration from the beginning of the clinical symptoms to the parasite extraction was 168 days (5 months and two weeks), (32). Velev et al. $\left(2019^{\mathrm{b}}\right)$ presented a case of a 51year-old male with $D$. repens-invasion, localized in the tongue (36). We did not find studies with analyzes risk factors using a multivariate approach, but we believe that the dynamics of the spread of Dirofilaria-invasion is related to climate and social factors. The growing number of infections in Bulgaria, as well as worldwide, due to global climate change and the active migration of people and their accompanying pets, suggests the need for better diagnosis and registration of cases $(4,6$, $8)$.

\section{Possibilities for diagnosis dirofilariasis}

According to many authors, including from Bulgaria, due to the nature of the disease and the small number of cases, diagnosis is difficult to be defined. The most common diagnoses are neoplasms, lymphadenitis with unknown aetiology, hydrocele, lipoma, dermoid cyst, fibroadenoma, neurofibroma, allergic conjunctivitis. The authors indicate that serological diagnosis does not significantly contribute to the detection and identification of the parasite in humans, and therefore could only be used as a screening method $(30,31)$.

The lack of diagnostic tests to determine the dirofilariasis invading humans causes the unreliability of the facts about the spread of dirofilariasis caused by either D. repens or $D$. immitis (6). The females of $D$. repens are viviparous and after mating, microfilariae are released in the peripheral blood (diagnostic stage in the definitive hosts). In filarial infections, the immunological response is mainly caused by microfilariae which rarely develop into sexually mature specimens in humans.

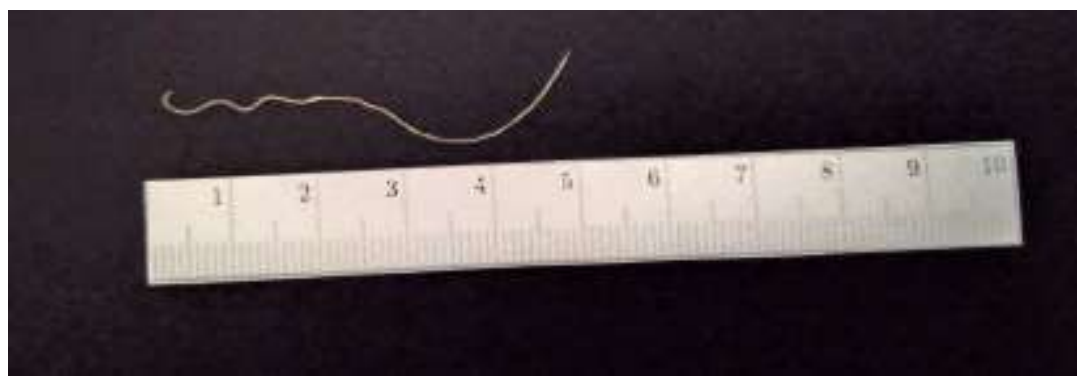

Figura 1a. D. repens $70 \mathrm{~mm}$ long (Imagine Chakarova B.)

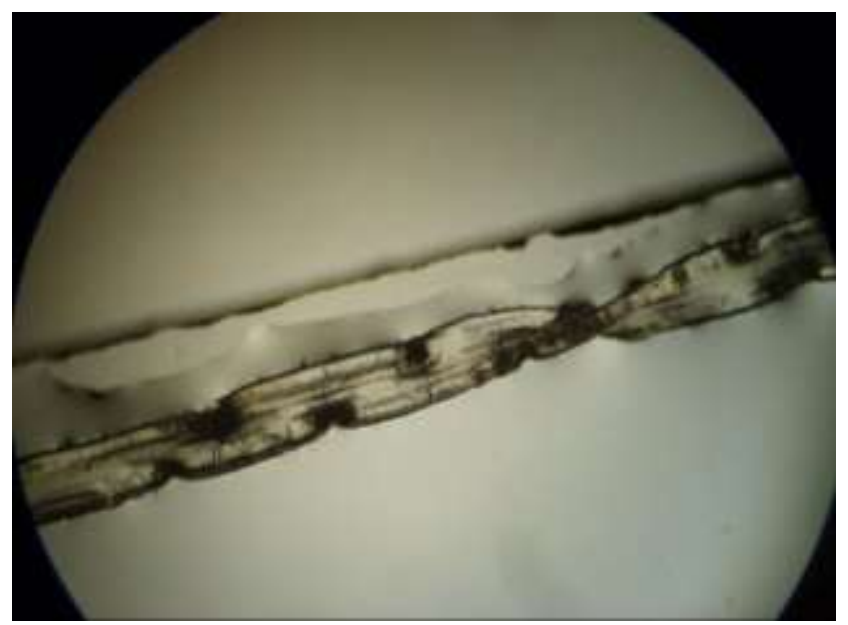

Figura 1b. Microphotography D. repens - can be seen longitudinal ridges of the cuticle (Imagine Chakarova B.) 
If the infection occurs as larva migrans, especially in the subconjunctiva, and the patient was not exposed to other potential causes of larva migrans, the clinical picture is highly suggestive of $D$. repens. The anamnesis should exclude the visit of the patient to endemic areas of other filaria, such as Loa loa in Africa. In case of intraocular cysts or subcutaneous nodules, the diagnosis is more difficult, but a live moving worm can be seen using a pre-operative high-resolution ultrasound $(1,38,39)$. In humans, D. repens usually reaches in its biological development to larvae of the third stage (L3) with dimensions usually $60-120 \mathrm{~mm}$ long by 350 $\mu \mathrm{m}$ wide (Figures 1a, b). The most distinctive features of are the longitudinal ridges of the cuticle, which are not present in any other filarial worm infecting humans (Figures 2a, b).

In most cases, in people infected with $D$. repens antibodies against the filaria are not found or very low titres can be found (40). Such low titres can be observed in other nematode infections due to cross-reacting antibodies (1). Development of diagnostics has been reported, based on the purified somatic antigen of immature female $D$. repens, removed from humans, and the application of their results have ambiguous diagnostic value $(41,42)$. Serodiagnosis can be a good alternative to invasive diagnostics since surgery is avoided; hidden invasions can be detected, facilitating therapeutic and epidemiological studies (43). However, serology has its drawbacks: in the first place it is not possible to determine the different level of the positive and negative predictive value of the test performed; these tests are still in the experimental field and are not yet commercially available. The problem is the existence of higher seroprevalence in humans exposed to mosquitoes - possible vectors in endemic areas. This must always be taken into account before interpreting the results of immunodiagnostics (40, 43-45). Molecular and biological techniques can be applied as modern methods (46). These methods (PCR) are included in the diagnostic kit in cases of uncertain diagnosis, especially in endemic areas (47). In the case of intraocular cysts or subcutaneous nodes, diagnosis is more difficult, but a living moving worm can be seen using high-resolution preoperative ultrasound $(38,39)$. In the microscopic examination, female specimens of $D$. repens do not usually contain microfilariae. Distinctive and most characteristic features of D. repens are the longitudinal ridges of the cuticle, which are not found in any other member of the filariae family diagnosed in humans (48). Serological studies are not useful in human cases. Therefore, in most cases of people with $D$. repens antibodies against the filaria are not found, or very low titres can be found $(40,43)$. However, such low titres are also observed in other nematode infections due to cross-reacting antibodies. Analysis of blood samples by microscopy or PCR is not useful for the same reason. Szenasi et al. (2008) provided an overview of about 2,000 cases identified so far in Hungary, as well as 16 new cases ( 8 men and 8 women) with an average age of 60 , of which 8 cases with ocular localization, 7 with subcutaneous localization. In one case, dirofilariasis was diagnosed histologically after removal of an axillary lymph node in a patient with lymphoid leukaemia. Patients had not travelled abroad. According to the authors, most cases of dirofilariasis were the result of autochthonous invasions. The authors suggested that with increasing the number of cases, this parasitic disease would become more important in Central Europe, which would increase with the improvement of the clinical diagnosis (49). Ilyasov et al. (2013) presented D. repens as a worm causing subcutaneous dirofilariasis, characterized by the development of benign subcutaneous nodes resembling skin tumours and ocular dirofilariasis with orbital, eyelid, conjunctival, retroocular and intraocular locations. According to the authors, intraocular and retroocular dirofilariasis caused significant damage and discomfort to patients because of the presence of worms and their surgical removal. They described a case of a 20-yearold woman in north-western Russia. She visited an ophthalmologist for pain and redness of the skin, as well as swelling of the inner corner of the left upper eyelid. The swelling sequentially migrated to the temporal zone, the lower eyelid and the inner corner of the lower eyelid. The results of the study were within normal limits. After about four subsequent relapses (about four weeks after the initial symptoms and signs), CT scan of the paranasal sinuses and orbits was performed. The scan revealed a $12 \times 13 \times 14 \mathrm{~mm}$ soft tissue structure behind the left eyeball and adjacent medial tear to the optic nerve. No other abnormalities in 
the visible area of the brain and sinuses were detected (50).

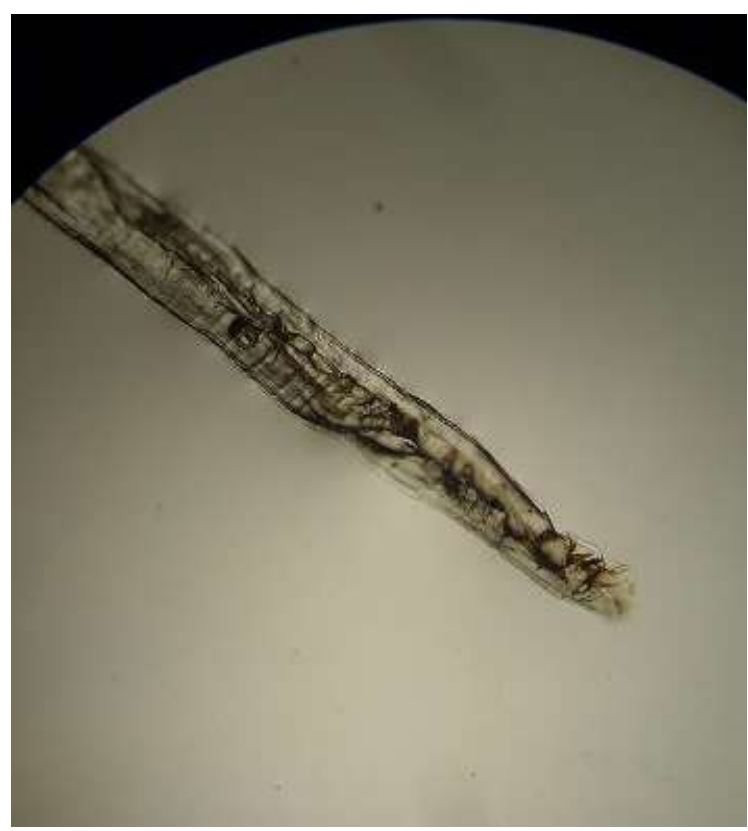

Figure 2a. Front end of $D$. repens

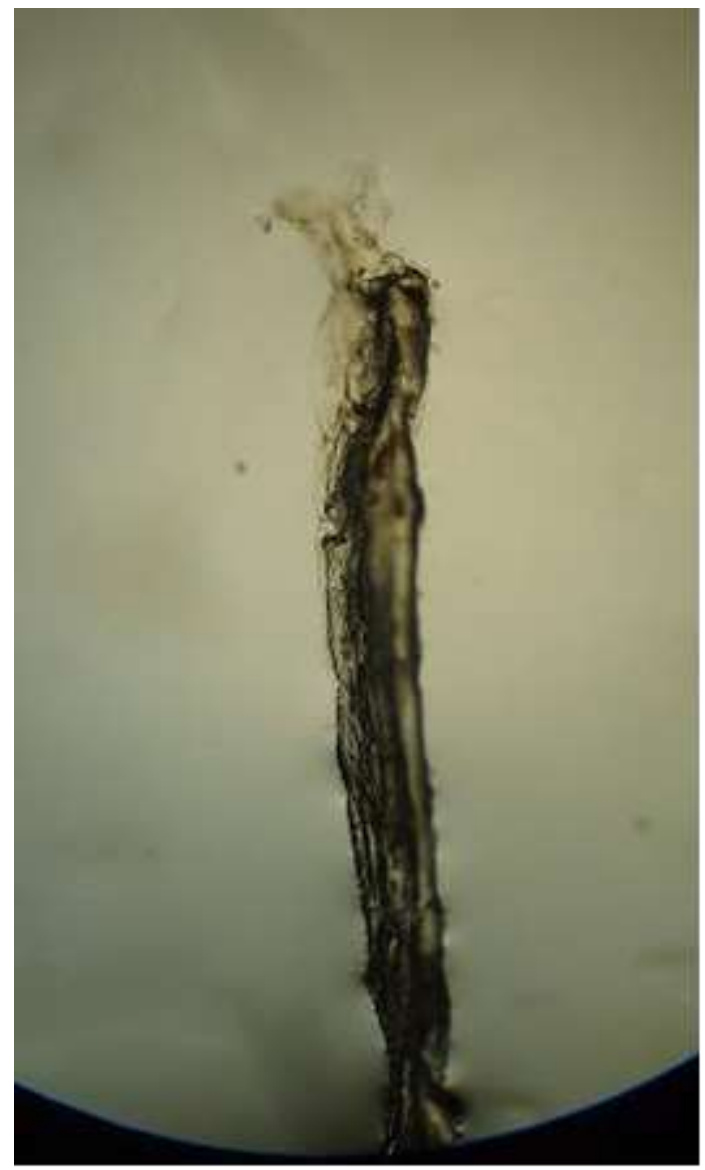

Figure 2b. Tail end of D. repens

A month later, magnetic resonance imaging (MRI) confirmed the presence of a cystic structure with irregular rounded shape; smooth borders closely adhered to the eyeball and the optic nerve (50). On T2w images, the lesion was found to have a high-density core and lowdensity surrounding tissue. It was found that the adjacent retrobulbar tissue was slightly swollen, the optic nerve was displaced medially and downward, and the adjacent upper muscle was displaced medially and upward (50). A retroocular cystic lesion was proven in the left orbit with a well-shaped capsule and high density but heterogeneous nucleus structure. Through high-resolution ultrasound, a well-defined $3 \mathrm{~mm}$ wall was found resembling a cyst containing fluid and a tightly wound internal structure that appeared to move actively. The diagnosis was retroocular parasite Dirofilaria spp. The worm was removed by a transpalpebral orbitotomy. A live roundworm was removed from the cyst with dimensions $80 \times 0.6 \mathrm{~mm}$ (50). By conventional PCR, a roundworm of the Dirofilaria repens species was identified. CT and MRI have been used as successful diagnostic methods for dirofilariasis by other authors (50-53).

\section{CONCLUSION}

The data on the cases of dirofilariasis in Bulgaria are incomplete and inaccurate, as at this stage the national legislation does not require the registration of cases of dirofilariasis in humans.

With the global climate changes, the increased migration flow and the accompanying problems, prognostic hypotheses are formed for expanding the areas of vector-transmitted zoonotic infections and invasions.

The combination of serological, histological, molecular, CT and MRI methods and techniques increases the diagnostic possibilities in human heartworm disease.

\section{REFERENCES}

1. Capelli, G. Genchi, C., Baneth, G., Bourdeau, P., Brianti, E., Cardoso, L., Danesi, P., Fuehrer, H., Giannelli, A., Ionică, A., Maia, C., Modrý, D., Montarsi, F., Krücken, J., Papadopoulos, E., Petrić, D., Pfeffer, M., Savić, S., Otranto, D., Poppert, S., Silaghi, C. Recent advances on Dirofilaria repens in dogs and humans in Europe. Parasites \& Vectors, 11:663, 2018. https://doi.org/10.1186/s13071-0183205-x

2. Etymologia: Dirofilaria. Emerging Infectious Diseases (CDC), 20:2, 2014. 
3. Muro, A., Genchi, C., Cordero, M., Simon, F. Human Dirofilariasis in European Union. Parasitology Today, 15(9):386389, $\quad 1999 . \quad$ doi: $10.1016 /$ s01694758(99)01496-9

4. Pistey, W. R. Studies on the Development of Dirofilaria tenuis Chandler 1942. The Journal of Parasitology, 44(6):613-626, 1958. doi: $10.2307 / 3274546$

5. Orihel, T.C., Eberhard, M.L. Zoonotic filariasis. Clin Microbiol Rev. 11:366-88, 1998

6. Pampiglione, S., Rivasi, F. Human dirofilariasis due to Dirofilaria (Nochtiella) repens: an update of world literature from 1995 to 2000. Parasitologia, 42:231-254, 2000. PMID: 11686084

7. Vezzani, D., Carbajo, A.E. Spatial and temporal transmission risk of Dirofilaria immitis in Argentina. Int. J. Parasitol. 36, 1463-1472, 2006.

8. Simón, F., Siles-Lucas, M., Morchón, R., González-Miguel, J., Mellado, I., Carretón, E., Alberto Montoya-Alonsoc, J. Human and Animal Dirofilariasis: the Emergence of a Zoonotic Mosaic. Clinical Microbiology Reviews, 25(3):507-544, 2012. doi:10.1128/CMR.00012-12

9. Salamatin, R. V., Pavlikovska, T. M., Sagach, O. S., Nikolayenko, S. M., Kornyushin, V. V., Kharchenko, V. O., Masny, A., Cielecka, D., KoniecznaSałamatin, J., Conn, D.B., Golab, E. Human dirofilariasis due to Dirofilaria repens in Ukraine, an emergent zoonosis: epidemiological report of 1465 cases. Acta Parasitol, 58:592-8, 2013. doi: 10.2478/s11686-013-0187-x

10. Șuleșco, T., Volkova, T., Yashkova, S., Tomazatos, A., von Thien H., Lühken, R., Tannich, E. Detection of Dirofilaria repens and Dirofilaria immitis DNA in mosquitoes from Belarus. Parasitol Res, 115:3535-41, 2016. doi: 10.1007/s00436016-5118-y

11. Tomazatos, A., Cadar, D., Török, E., Maranda, I., Horváth, C., Keresztes, L., Spinu, M., Jansen, S., Jöst, H., SchmidtChanasit, J., Tannich, E. Circulation of Dirofilaria immitis and Dirofilaria repens in the Danube Delta Biosphere Reserve, Romania. Parasites \& Vectors, 11:392, 2018. https://doi.org/10.1186/s13071-0182980-8
12. Kłudkowska, M., Pielok, Ł., Frąckowiak, K., Masny, A., Gołąb, E., Paul, M. Dirofilaria repens infection as a cause of intensive peripheral microfilariemia in a Polish patient: process description and cases review. Acta Parasitol, 63(3):657663, 2018. doi: 10.1515/ap-2018-0077.

13. Grigor'eva, M.V., Dvorovenko, E.V. Dirofilariasis of testicular membranes under a mask of the syndrome of edematic and hyperemic scrotum. Pediatric Surgery, $2,15,2003$

14. Kim, M. K., Kim, C. H., Yeom, B. W., Park, S. H., Choi, S. Y., Choi, J. S. The First Human Case of Hepatic Dirofilariasis. J Korean Med Sci, 17, 68690, 2002

15. Džamić, A.M., Čolović, I.V., ArsićArsenijević, V.S., Stepanović, S., Boričić, I., Džamić, Z., Mitrović, S.M., Rašić, D.M., Stefanović, I., Latković, Z., Kranjčić-Zec, I.F. Human Dirofilaria repens infection in Serbia. J Helminthol, 83, 129-137, 2009

16. Martín, S. F. Human dirofilariosis in the Mediterranean Basin. Review of the epidemiological and parasite/host relationships knowledge. Abstr., Second European Dirofilaria Days, 16-18 Sept Salamanca, Spain, 167-174, 2009

17. Vieira, A. L., Vieira, M. J., Oliveira, J. M., Simões, A. R., Diez-Baños, P., Gestal, J. Prevalence of canine heartworm (Dirofilaria immitis) disease in dogs of central Portugal. Parasite, 21:5, 2014. doi:10.1051/parasite/2014003

18. Georgieva, D.A., Ivanov, I., Prelesov, P.N. Studies on the parasitic fauna in stray dogs in the Stara Zagora region. Bulg. J. Vet. Med., 2, 2-3, 121 - 124, 1992

19. Georgieva, D., Z. Kirkova, A. Ivanov. A study on the incidence and diagnosistics of dirofilariasis (Heartworm disease) in carnivores. Bulgarian Journal of Veterinary Medicine, 4, 4, 2001

20. Kirkova Z., Raychev, E., Georgieva, D. Studies on feeding habits and parasitological status of red fox, golden jackal, wild cat and stone marten in Sredna gora, Bulgaria. Journal of Life Sciences, 5(4), 36, 264-270, 2011

21. Radev, V., Lalkovski, N., Zhelyazkov, P., Kostova, T., Sabev, P., Nedelchev, N., Vassileva, R. Prevalence of gastrointestinal parasites and Dirofilaria spp. in stray dogs from some regions in 
Bulgaria. Bulg. J. Vet. Med., 19(1): 57 62, 2016, doi: 10.15547/bjvm.872

22. Iliev, P., Kirkova, Z., Ivanov, A., Kalkanov, I. Retrospective analysis on helminthic and protozoan infections in dogs and cats in Bulgaria. Bulg. J. Vet. Med., 20, (Suppl 1): 389 - 393, 2017

23. Jokelainen, P., Mõtsküla, P. F., Heikkinen, P., Ülevaino, E., Oksanen, A., Lassen, B. Dirofilaria repens Microfilaremia in Three Dogs in Estonia. Vector-Borne and Zoonotic Diseases, 16(2):136-138, 2016.doi:10.1089/vbz.2015.1833

24. Genchi, C., Rinaldi, L., Mortarino M., Genchi, M., Cringoli, G. Climate and Dirofilaria infection in Europe. Veterinary Parasitology, 163, 286-292, 2009

25. Kramer, L. H., Kartashev, V. V., Grandi, G., Morchón, R., Nagornii, S. A., Karanis, P., Simón, F. Human Subcutaneous Dirofilariasis, Russia. Emerging Infectious Diseases, 13, 1, 150-152, 2007

26. Vutchev, D., Dimitrov, H., Drandarska, I., Chakarova, B., Angelov, I., Gogov, T., Stancheva, G., Chergova, M., Marinova, E., Mladenova, S., Dimova, P., Koruev, A. Dirofilariatosis caused by Dirofilaria repens clinical observations. Problems of infectious and parasitic diseases, 31(2): 36-37, 2003.

27. Vutchev, D, Mikov, O. Dirofilariatosis in humans. DDD Bulletin, 1-4:106-110, 2004.

28. Daskalova M., Balabanov, C., Popovska, S., Rainova, I. Case of dirofilariasis in lower eyelid. Infectology, 13(1):39-40, 2006.

29. Harizanov, R., Jordanova, D., Bikov, I., Kaftandjiev, I. Cases of human dirofilariasis in Bulgaria 2009. In: Abstracts of the VIII National congress of clinical microbiology and infections of Bulgarian association of microbiologists. Plovdiv, April, pp. 35,2010.

30. Harizanov, R.N., Jordanova, D.P., Bikov, I.S. Some aspects of the epidemiology, clinical manifestations, and diagnosis of human dirofilariasis caused by Dirofilaria repens. Parasitol Res. 113(4): 1571 1579, 2014, doi: 10.1007/s00436-0143802-3.

31. Chakarova, B., Galabova, M., Tsachev, I., Neichev, I., Ananiev, J., Dimov, I., Andonov, S., Shomov, G., Ruskova, K., Petrov, P. Dirofilariasis in humans - new clinical cases of Southeast Bulgaria.
International Conference "Fundamental and Applied Aspects of the Study of Parasitic Arthropods in the 21st Century" St. Petersburg, October 21-25, , p. 185186, 2013

32. Chakarova, B., Dimov, I., Andonov, S., Shomov, G., Petrov, P. Three cases of subcutaneous dirofilariasis (D. repens) in patients from Southeast Bulgaria. Arhimed Journal of Science and Practice, 3:3-8, 2014.

33. Neichev, I., Slaveykov, K., Trifonova, K., Chakarova, B. Subconjunctival Dirofilaria repens. Acta Medica Bulgarica, 41(1): 9598, 2014.

34. Kaftandjiev, I .T., Harizanov, R. N. Rare case of epididymal dirofilariasis. QJM, 2016; doi: 10.1093/qjmed/hcw034

35. Velev, V'., Pelov, T., Garev, T., Peev, S., Kaftandjiev, I., Harizanov, R. Epididymal Dirofilariasis in a Child. First Case Report from Bulgaria. Med Princ Pract, 28(1):9698, 2019; doi: 10.1159/000494619.

36. Velev. $\mathrm{V}^{\mathrm{b}}$., M. Popov, M. Pavlova, M Karageorgiev, A. Mangarov. Tongue infection caused by Dirofilaria repens. QJM: An International Journal of Medicine, 112(8), 1-2, 2019, doi: 10.1093/qjmed/hcz135

37. Velev V $\mathrm{V}^{\mathrm{c}}$., Vutova, K., Pelov, T., Tsachev, I. Human Dirofilariasis in Bulgaria Between 2009 and 2018. Helminthologia.; 56(3): 247-251, 2019 doi: 10.2478/helm2019-0016

38. Gopinath, T. N., Lakshmi, K. P., Shaji, P. C., Rajalakshmi, P. C. Periorbital dirofilariasis-clinical and imaging findings: live worm on ultrasound. Indian $J$ Ophthalmol, 61(6):298-300, 2013. http://www.ijo.in/text.asp?2013/61/6/298/1 14111

39. Vucaj, C. V., Dobrosavljev, M., Niciforovic, D., Donat, D., BogdanovicStojanovic, D., Jukovic, M. Dirofilariasis of the breast: sonographic appearance. $J$ Clin Ultrasound, 42(7):433-5, 2014. doi: 10.1002/jcu.22139

40. Cancrini, G., Allende, E., Favia, G., Bornay, F., Antón, F., Simón, F. Canine dirofilariasis in two cities of southeastern Spain. Vet Parasitol, 92 (1):81-6, 2000 doi:10.1016/s0304-4017(00)00270-3

41. Bezkrovnaya, Y. G., Nagorny, S. A., Vaserin, Y. V. The method of extraction of the pure somatic antigen of Dirofilaria repens (in Russian). Patent for invention 
No. 2356575. Registered in the state register of the Russian Federation, May 27, 2009.

42. Ermakova, L. A., Nagornya, S. A., Krivorotova, E. Y., Pshenichnaya, N. Y., Matina, O. N. Dirofilaria repens in the Russian Federation: current epidemiology, diagnosis, and treatment from a federal reference center perspective. International Journal of Infectious Diseases, 23:47-52, 2014. doi: 10.1016/j.ijid.2014.02.008

43. Cancrini, G., Prieto, G., Favia, G., et al. Serological assays on eight cases of human dirofilariasis identified by morphology and DNA diagnostics. Ann Trop Med Parasitol, 93:147-52, 1999.

44. Espinoza, E., Cordero, M., Muro, A. AntiDirofilaria immitis IgE: seroepidemiology and seasonal variation in an exposed human population. Trop Med Parasitol, 44:172-6, 1993. PMID: 8256091

45. Perera, L., Muro, A., Cordero, M. Evaluation of a $22 \mathrm{kDa}$ Dirofilaria immitis antigen for the immunodiagnosis of human pulmonary dirofilariasis. Trop Med Parasitol, 45:249-52, $1994 . \quad$ DOI: 10.1046/j.1365-3156.1998.00209.x

46. Favia, G., Lanfrancotti, A., Della Torre, A., Cancrini, G., Coluzzi, M. Advances in the identification of Dirofilaria repens and Dirofilaria immitis by a PCR - based approach. Parassitologia, 39:401-2, 1997. PMID: 9802101

47. Marusić, Z., Stastny, T., Kirac, I., Stojcević, D., Kruslin, B., Tomas, D. Subcutaneous dirofilariasis caused by Dirofilaria repens diagnosed by histopathologic and polymerase chain reaction analysis. Acta Dermatovenerol Croat, 16(4):222-5, 2008. PMID: 19111148

48. Yilmaz, E., Fritzenwanker, M., Pantchev, N., Lendner, M., Wongkamchai, S., Otranto, D., Kroidl, I., Dennebaum, M., Le, T. H., Le, T. A., Ramünke, S., Schaper, R., von Samson-Himmelstjerna, G., Poppert, S., Krücken, J.. The
Mitochondrial Genomes of the Zoonotic Canine Filarial Parasites Dirofilaria (Nochtiella) repens and Candidatus Dirofilaria (Nochtiella) Honkongensis Provide Evidence for Presence of Cryptic Species. PLoSNegl Trop Dis, 10(10):e0005028, 2016.

49. Szenasi, Z., Kovacs, A. H., Pampiglione, S., Fioravanti, M. L., Kucsera, I., Tanczos, B., Tiszlavicz, L. Human dirofilariasis in Hungary: an emerging zoonosis in central Europe. Wien Klin Wochenschr, 120/3-4: 96-102, 2008. DOI 10.1007/s00508-0080928-2

50. Ilyasov, B, Kartashev, V., Bastrikov, N., Morchón, R., González-Miguel, J., Simón, F. Delayed Diagnosis of Dirofilariasis and Complex Ocular Surgery, Russia. Emerging Infectious Diseases, 19(2):326328, 2013.2 DOI: http://dx.doi.org/10.3201/eid1902.121388

51. Groell, R., Ranner, G., Martin, M. Uggowitzer and Hannes Braun. Orbital Dirofilariasis: MR Findings. AJNR Am J Neuroradiol, 20:285-286, 1999.

https://doi.org/10.1371/journal.pntd.00045 47

52. Eccher, A., Dalfior, D., Gobbo, S., Martignoni, G., Brunelli, M., Decaminada, W., Bonetti, F., Rivasi, F., Barbareschi, M., Menestrina, F. Periorbital Subcutaneous Tumor-Like Lesion Due to Dirofilaria repens. International Journal of Surgical Pathology, 16(1):101-103, 2008. http://online.sagepub.com

53. Hrčkova, G., Kuchtová, H., Miterpáková, M., Ondriska, F., Cibíček, J., Kovacs, Š. Histological and molecular confirmation of the fourth human case caused by Dirofilaria repens in a new endemic region of Slovakia. Journal of Helminthology, 87:85-90, 2013. doi:10.1017/S0022149X12000077 